http://dx.doi.org/10.23857/dom.cien.pocaip.2019.5.3.julio.589-602

URL:http://dominiodelasciencias.com/ojs/index.php/es/index

Ciencias de la educación

Artículo de investigación

\title{
El comercio justo como alternativa para desarrollar estrategias en beneficio de los productores
}

Fair trade as an alternative to develop strategies in benefit of producers

\section{Comércio justo como alternativa para desenvolver estratégias para o benefício dos produtores}

\author{
Laura Patricia Muñiz-Jaime I \\ laura.muniz@unesum.edu.ec \\ María Lisseth Vinueza-Ramírez II \\ mariavinueza@gmail.com \\ Gino Iván Ayón-Ponce III \\ ginoayon1@hotmail.com
}

Recibido: 15 de febrero de 2019 *Aceptado: 04 de junio de $2019 *$ Publicado: 05 de julio de 2019

\footnotetext{
Magíster en Contabilidad y Auditoría, Economista, Docente de la Universidad Estatal del Sur de Manabí, Jipijapa, Ecuador. Jipijapa, Ecuador.

III. Magíster en Administración de Empresas, Magíster en Gerencia Educativa, Ingeniero Comercial, Docente de la Universidad de Laica Eloy Alfaro de Manabí, Manabí, Ecuador.
} 


\section{Resumen}

Este articulo tiene como propósito el análisis del Comercio Justo como alternativa para desarrollar las estrategias en beneficio de los pequeños productores de los países para poner su esfuerzo laboral en el mercado internacional, este movimiento tiene como finalidad promover la justicia y equidad entre los productores para que sus productos sean comercializados de manera justa y con precios cómodos que aporten directamente a la producción nacional para transformar y mejorar la cadena productiva.

La metodología de esta investigación fue un estudio bibliográfico que fue de gran importancia en la obtención de información y se obtuvo como resultado que Ecuador es un país que también conforma este movimiento de intercambio comercial y que sus organizaciones buscan el beneficio mutuo con la finalidad de que aquellos productores y productoras tengan una condición de buen vivir el cual otorgue un papel primordial al Comercio Justo.

Palabras Claves: Comercio justo; estrategias; canales de comercialización; beneficio.

\section{Summary}

This article aims at the analysis of Fair Trade as an alternative to develop strategies for the benefit of small producers in countries to put their labor effort in the international market, this movement aims to promote justice and equity among producers so that Its products are marketed fairly and with comfortable prices that contribute directly to national production to transform and improve the production chain.

The methodology of this research was a bibliographic study that was of great importance in obtaining information and it was obtained as a result that Ecuador is a country that also forms this commercial exchange movement and that its organizations seek mutual benefit in order to those producers and producers have a condition of good living which gives a fair role to Fair Trade.

Keywords: Fair Trade, Strategies, Marketing Channels, Profit

\section{Resumo}


Este artigo tem como objetivo a análise do Comércio Justo como uma alternativa para desenvolver estratégias em benefício dos pequenos produtores nos países para colocar seus esforços de trabalho no mercado internacional, este movimento visa promover a justiça e equidade entre os produtores para que Seus produtos são comercializados de forma justa e com preços confortáveis que contribuem diretamente para a produção nacional para transformar e melhorar a cadeia produtiva. A metodologia desta pesquisa foi um estudo bibliográfico que foi de grande importância na obtenção de informações e obteve-se como resultado que o Equador é um país que também forma esse movimento de intercâmbio comercial e que suas organizações buscam benefício mútuo para esses produtores e produtores têm uma condição de boa vida que dá um papel justo ao Comércio Justo.

Palavras-chave: Comércio justo; estratégias; canais de marketing; lucro.

\section{Introducción}

Las primeras experiencias de comercio alternativo se ubican en Estados Unidos alentadas por grupos religiosos a finales de la década de los 40's. En 1958 se abrió la primera tienda formal de Comercio Justo en Estados Unidos. En 1969 se inaugura la primera tienda del "Tercer Mundo" como punto de venta para los productos del sur y rápidamente se convierten en una red de tiendas que actualmente se halla en 20 países. Estas tiendas además trabajan en campañas de concientización a nivel de consumidores, dando a conocer información sobre la producción, los productores y sus condiciones de vida. El termino Comercio Justo apareció en la primera conferencia de la Organización de Comercio y Desarrollo de las Naciones Unidas (UNCTAD) de Ginebra, en 1964, cuando los países no alineados ponen en cuestión los términos injustos en los que se desarrolla el comercio internacional, y reclaman dar mayor importancia al establecimiento de las relaciones comerciales igualitarias entre los países del Sur y del Norte (Cecj-Ecuador, 2015)

Esta forma alternativa de comercio alentó a varias Organizaciones No Gubernamentales (ONG) de África, Asia y América Latina a fortalecer procesos de apoyo y asesoría a pequeños productores con la finalidad de establecer vínculos con las organizaciones del Norte. El Comercio Justo se amplió y en 1973, Fair Trade Original, en los Países Bajos importo de Guatemala el primer café “comercializado con justicia", a partir de ello productos se han diversificado e incluye productos 
como el té, cacao, azúcar, vino, jugos de frutas, arroz, algodón, flores, etc, lo que ha permitido también nuevos mercados a nivel de instituciones, supermercados y tiendas especializadas. (CecjEcuador, 2015)

El objetivo principal de esta investigación es analizar el Comercio Justo como alternativa para desarrollar estrategias en beneficios a los productores, la realización de esta indagación la realice mediante la examinación de las diferentes teorías, conceptos e importancia sobre el tema y su vez determinar cuál son las principales estrategias que utiliza el Comercio Justo para los productores y a su vez establecer los beneficios que obtendrán los productos con la implementación del Comercio Justo pudiendo determinar la factibilidad de efectuar este sistema como parte fundamental para el crecimiento y desarrollo de los productores que en ocasiones son marginalizados.

\section{Desarrollo}

\section{El comercio justo y su importancia}

El Comercio Justo es un movimiento internacional que tiene como objetivo fomentar la justicia global a través de la comercialización de los productos elaborados en condiciones justas, la movilización social y el suceso político, este movimiento denuncia los orígenes de la pobreza y desigualdad desarrollando así un sistema comercial alternativo convenido en el que los derechos de los pueblos y del medio ambiente estén en el centro de la actividad económica, en la actualidad en la red de Comercio Justo existen más de 2000 organizaciones productoras en África, Asia y América Latina que agrupan más de 2 millones de personas productoras y trabajadoras. (Solidaria, s.f.)

El Comercio Justo tiene como finalidad establecer relaciones más justas y equitativas de comercio a través de las diferentes prácticas sociales y el ejercicio de valores que permiten una relación más directa entre los productores y los consumidores, es el intercambio comercial basado en el dialogo, la transparencia y el respeto que busca una mayor equidad en el comercio internacional y a la vez contribuye al desarrollo sostenible ofreciendo mejores condiciones comerciales y asegura los derechos de los pequeños productores y trabajadores. (Cecj-Ecuador, 2015) 
La distribución de los productos es realizada a través de las organizaciones importadoras que establecen los precios de común acuerdo con las organizaciones productoras ya que les facilitan la prefinanciación y les asesoran para mejorar su comercialización, los productos de Comercio Justo se venden en diferentes tiendas, hostelerías ya que en estos lugares se pueden encontrar una amplia gama de productos como ropa, juguetes, alimentos, entre otros. (Solidaria, s.f.)

El Comercio Justo calza perfectamente dentro de las prácticas de la economía de solidaridad que es un nuevo enfoque conceptual al nivel de la teoría económica ya que se refiere a las formas económicas cooperativas, asociativas y comunitarias, donde la solidaridad se inserta en la economía para gestar un nuevo ser humano y una nueva sociedad, surgió con la finalidad de favorecer a los y las personas socialmente excluidos y desfavorecidos para generar nuevas relaciones económicas, sociales y políticas. (CLAC, 2014)

El Comercio Justo se lo entiende como una forma de cambios estructurales que permiten humanizar la actividad económica y enfrentar los diversos problemas de pobreza, la marginación e injusticia, además también se entiende que es un proceso que desata el desarrollo de los talentos humanos y de las capacidades organizativas y de gestión fomentando el empoderamiento de las personas, organizaciones y empresas, construyendo al mismo tiempo nuevas relaciones económicas y comerciales que contribuyen al buen vivir. (Cecj-Ecuador, 2015)

\section{Ventajas}

- Los productos forman parte de cooperativas u organizaciones voluntarias y funcionan democráticamente.

- Rechazo a la explotación infantil.

- Igualdad entre hombres y mujeres.

- Se trabaja con dignidad respetando los derechos humanos.

- El precio que se paga a los productores permite condiciones de vida dignas.

- Se valora la calidad y la producción ecológica

- Respeto al medio ambiente

- Se busca la manera de evitar intermediarios entre productores y consumidores. 
- Se informa a los consumidores acerca del origen del producto.

- Es un proceso voluntario, tanto en la relación entre los productores, los distribuidores y los consumidores. (Sites, s.f.)

El Comercio Justo se enfoca en desarrollar estrategias el cual los productores y consumidores obtengan un beneficio mutuo como es una estructura democrática que los productores deben cumplir para poder ser elegibles para su certificación y a su vez los consumidores apoyan a las empresas para que se comporten de acuerdo a sus principios ya que esto promoverá las condiciones económicas y sociales del mundo en desarrollo.

\section{Desventajas}

- Precios elevados

- Poca variedad de productos

- Pocos establecimientos y mal comunicados

- Falta de publicidad y de interés por parte de la sociedad. (Sites, s.f.)

Así como el Comercio Justo tiene sus ventajas este movimiento internacional también tiene sus desventajas ya que las cooperativas u organizaciones deben pagar una cuota y la mayoría de los productos de los países en vías de desarrollo no pueden pagar estas cuotas.

\section{Principios del comercio justo (Beneficios a los Productores)}

La Organización Mundial del Comercio Justo (WFTO) establece 10 principios que deben ser cumplidos por las organizaciones que trabajan en Comercio Justo, son los siguientes:

\section{Creación de Oportunidades para Productores en Desventaja Económica:}

La organización trata de reducir la pobreza apoyando a los pequeños productores marginalizados buscando mejorar la condición de vida de los individuos que se encuentren en una desigualdad económica. (WFTO, 2016)

\section{Transparencia y Responsabilidad - Rendición de cuentas}


Este principio se enfoca en buscar de manera apropiada y participativa involucrar a los empleados, miembros y productores en sus procesos de toma de decisiones. (WFTO, 2016)

\section{Prácticas Comerciales Justas}

Desarrolla el bienestar social, económico y ambiental de los pequeños productores que se encuentran marginados, ya que cumple de forma responsable y a su vez los proveedores respetan sus contratos y entregan puntualmente los productos con la calidad y descripción acordada. (WFTO, 2016)

\section{Pago de un Precio Justo}

Un precio justo es establecido mutuamente por todos los involucrados, a través del dialogo que consiste en dar un pago justo a los productores que se enfoca en la igualdad de la remuneración por el trabajo tanto para mujeres como para los hombres. (WFTO, 2016)

\section{No al Trabajo Infantil y al Trabajo Forzoso}

El movimiento se asegura que no haya labor forzosa en el lugar de trabajo, si existe un involucramiento de los niños/as en la elaboración de los productos debe ser público y no debe afectar de forma negativa el bienestar, la seguridad y la recreación de los niños/as. (WFTO, 2016)

\section{Compromiso con la No Discriminación, la Igualdad de Género y el Empoderamiento} Económico de la mujer y la Libertad de Asociación

Este movimiento mundial tiene una política clara y plan de promover la igualdad de género que se enfoca en garantizar que tanto las mujeres como los hombres tengan la oportunidad de acceder a los recursos que necesitan para ser productivos. (WFTO, 2016)

\section{Garantizar buenas condiciones de trabajo}

La organización ofrece un ambiente de trabajo seguro y sano para sus empleados y miembros además cumple con las leyes nacionales y regionales y los convenios de la OIT 
sobre la salud y seguridad, el horario y las condiciones de trabajo para los empleados. (WFTO, 2016)

\section{Desarrollo de Capacidades}

Las organizaciones trabajan directamente con los pequeños productores en el desarrollo de actividades específicas para ayudar a estos productores a mejorar sus habilidades de gestión y acceso a los mercados del Comercio Justo. (WFTO, 2016).

\section{Promoción del Comercio Justo}

Promueve los objetivos y actividades de acuerdo con las capacidades de la organización ya que esta proporciona a sus clientes información sobre sí misma, los productos que comercializa y las organizaciones productoras que elaboran y cosechan sus productos. (WFTO, 2016).

\section{Respeto por el Medio Ambiente}

El uso de la tecnología en la producción busca reducir el consumo de energía y siempre que sea posible usan tecnologías de energía renovable que minimizan las emisiones de gas de efecto invernadero que dañan al medio ambiente. (WFTO, 2016)

\section{Estrategias del comercio justo (Ecuador)}

De forma estratégica se entiende que el Comercio Justo se enfoca en dos dimensiones fundamentales:

La primera dimensión estratégicas es enfocarse en el cambio de relaciones y prácticas sociales de producción, comercialización, distribución y consumo para lograr justicia y equidad en el comercio mediante la incorporación de los principios y valores éticos que abarcan aspectos humanos, económicos, sociales y ecológicos y que a su vez contribuyen nuevas relaciones humanas sociales y geo-políticas y la segunda dimensión es la creación y ampliación de mercados para los productos y servicios que vienen de relaciones y prácticas de Comercio Justo. (CLAC, 2014)

El sumak kasuay o Buen Vivir reivindica los valores esenciales y los derechos del ser humano e introduce otras formas de entender su desarrollo, rescatando los principios de solidaridad estructural, igualdad, equidad, respeto de la naturaleza y trabajo digno, en este sentido el Comercio 
Justo contribuye directamente a la construcción del Buen Vivir puesto que implica la incorporación y puesta en práctica de un conjunto de principios y valores éticos a lo largo de toda la cadena de producción y comercialización, generando que los productores/as no solo accedan a mejores ingresos sino al gozo de una vida digna. (CLAC, 2014).

\section{Organizaciones Productoras: Ecuador}

\section{- Cumbres de INGAPI}

La organización se encuentra en la provincia de Pichincha al noroeste de Quito (Ecuador), se creó en 2003 y la forman alrededor de 50 familias son pequeños agricultores y agricultoras su principal cultivo es la caña de azúcar, aunque también plantan otros productos para consumo propio y para la venta local como la yuca, maíz, plátanos, limones y otras frutas. (Justo.ORG, s.f.)

\section{- Asociación PAKTA MINTALAY}

Nace en el 2010 con la finalidad de apoyar y participar de la comercialización equitativa de productos de alimentación y artesanales de los productores/as del campo y de barrios marginados, PATKA MINTALAY en quechua significa "comercio en equidad" comercializa preferentemente productos con certificación orgánica como la panela, setas, cacao, café, quinua. (Justo.ORG, s.f.)

\section{- Canarí}

Canarí es un término que significa en quechua "agrado" se constituyó en 1981, brinda apoyo en la comercialización y en la producción a través de cursos formativos y asesoría sus principales productos son los cereales, frutos secos, artesanía (en madera de balsa, cerámica, plata y coral negro). (Justo.ORG, s.f.)

\section{- Cooperativa el Paraíso}

Está formada por 21 socios agricultores situada en la provincia de Pichincha creada en 1992 con el fin de trabajar de forma asociada, mejorar la calidad del producto y buscar nuevos mercados, actualmente están implicadas 700 personas en la elaboración de la panela es envasada por la 
Fundación Maquita Cuschunchin que se encarga de su exportación a países europeos según los criterios del comercio Justo. (Justo.ORG, s.f.)

\section{- Corporación de talleres del Gran Valle}

Es una organización que se agrupa a los diversos productores está conformada por 120 familias situada en Valle de Manduriacos, tiene como finalidad crear talleres artesanales y pequeñas empresas y favorecer la comercialización de sus productos, produce artículos de baño (esponjas, guantes e baño, zapatillas) y decorativos (cajas, flores, etc.) (Justo.ORG, s.f.)

\section{- Maquita CUSCHUNCHIC}

Esta agrupada por unas 400 cooperativas situadas en zonas urbanas y rurales de Quito con sede en varias provincias posee 5300 trabajadores su sistema organizativo y democrático y participativo, la mitad de los cargos en las directivas son mujeres, producen productos de alimentación, textil para el hogar, ropa. (Justo.ORG, s.f.)

\section{- Telemujeres}

Es una cooperativa formada por mujeres de zonas rurales situada en Azuay, entre sus objetivos se destacan la capacitación técnica de las socias, la participación de sus miembros en la comunidad y promover la actividad artesanal como tradición cultural, nació en 1992 elaboran ropa, artículos de decoración de cocina, complementos, juguetes, perfumes, esencias, alimentación (café, té, chocolates, miel) (Justo.ORG, s.f.)

\section{Resultados}

- La asociación de agricultores y agricultoras y ganaderos Cumbres de Ingapi en la actualidad gracias al Comercio Justo los productores y productoras han conseguido salir de la marginalización y la pobreza, ya que han mejorado su calidad de vida y la de sus familiares por ejemplo con el acceso a la educación para sus hijos, disponiendo de formación técnica para los socios y socias y también pudiendo invertir en mejoras en la producción. (Alternativa3, 2017) 
- La asociación Pakta Mintalay consiguió que su impacto cause la comercialización y se vea reflejada en la mejora de las condiciones de vida de las familias participantes, es una empresa que realiza comercio exterior con identificador tributario ha realizado 205 registros y ha obtenido $\$ 1,310,005$ en los últimos 5 años. (Veritrade, 2015)

- Canarí es una de las instituciones que ha obtenido la certificación al Sistema de Gestión de la Calidad ISO 9001-Version 2008 por su administración empresarial enfocada en las personas y responsabilidad social, las ventas se han incrementado en el 2014 en más de doscientos millones, los productos comercializados son \$2.148.017 agropecuarios naturales \$255.249 en artesanales, \$911.571 para transformados.. (FEPP, 2014).

- La Cooperativa El Paraíso ha obtenido beneficios ya que sus ventas ayudan a dar un salario justo a sus trabajadores y trabajadoras, se financia la escuela de la comunidad y se equipa y mantiene un centro odontológico, a su vez se ha logrado obtener la certificación de agricultura ecológica del azúcar que procede de las plantaciones de caña de la cooperativa, además planes de mejoras continua en la calidad del producto, así como también la formación constante para los trabajadores y trabajadoras. (Alternativa3, 2017).

- La corporación Talleres del Gran Valle es un ejemplo de cooperativismo y éxito disponen de un centro de acopio denominado Casa del Agricultor donde reciben y acopian tilapia, frejol, maíz y maní, una de sus iniciativas es que forman parte de la cooperativa mujeres de que producen artesanías de gran calidad gracias a estas iniciativas los habitantes del Valle de Manduriacos tienen una mejor calidad de vida. (Reciprocco.org, 2013)

- Maquita Cuschunchic, incorporo tecnología amigable con el ambiente e innovación para mejorar la eficiencia del trabajo, contribuyo a la seguridad alimentaria a través de la diversificación de los cultivos, en el año 2015 tuvieron una cobertura directa de trabajo en 22.968,56 hectáreas en 11 provincias del Ecuador. (Maquita, 2016)

- La cooperativa Telemujeres se distingue porque el producto es imperceptible del detalle, lo que desean es mantenerla y poder comercializar a precio justo y poder exportar para que las nuevas generaciones también encuentren intereses en esta actividad, ellos se capacitan 
continuamente lo que ayuda a su crecimiento profesional y personal. (Artesanias.cidap, 2012).

\section{Discusión}

La Asolación Europea de Comercio Justo, EFTA, lo define como "una iniciativa que intenta corregir algunos de los países perjuicios que sufren pequeños productores y los trabajadores explotados. Quieren ser un símbolo de un comercio diferente, en el que todos ganen, tanto consumidores como productores, en el que los marginados puedan participar en la globalización en beneficio propio y no como explotados". (NICAISE, 2004).

El objetivo primordial de las organizaciones de Comercio Justo es luchar contra la pobreza de esos pequeños productores, a través de un nuevo sistema basado en valores humanos de justicia y equidad, en un marco libre, directo y honesto entre los tres actores que intervienen en el comercio como son los productores, consumidores e intermediarios. (Ruben Torres Medina, 2008).

Gracias al Comercio Justo muchas organizaciones a nivel mundial han podido establecer sus productos en puntos de ventas importantes y con precios accesibles para los consumidores este movimiento internacional empleado en diferentes países es primordial en el desarrollo de forma laboral, en el aspecto económico los pequeños productores que en ocasiones no tienen recursos suficientes para poder comercializar sus productos y que a su vez se no han pagado a un buen precio. Ecuador es un país rico en recursos, que se encuentra vinculado a un sistema que fomenta la equidad global orientada al desarrollo del Comercio Justo de una forma articulada que busca impulsar las relaciones de comercio entre los países que lo acojan.

\section{Referencias Bibliográficas}

Alternativa3. (24 de 04 de 2017). Alternativa3. Obtenido de Alternativa3:

http://alternativa3.com/?cooperativa=cooperativa-el-paraiso/

Artesanias.cidap. (2012). Artesanias.cidap. Obtenido de Artesanias.cidap:

http://artesanias.cidap.gob.ec/artesano/cooperativa-de-producci\%C3\%B3n-artesanaltejemujeres 
Camari.org. (s.f.). Camari.org. Obtenido de Camari.org:

http://www.camari.org/index.php/camari

Cecj-Ecuador. (2015). Cecj-Ecuador. Obtenido de Cecj-Ecuador:

http://www.cecjecuador.org.ec/comercio-justo/historia/

CLAC. (06 de 2014). CLAC. Obtenido de CLAC: http://www.clac-comerciojusto.org/ulcj/wpcontent/uploads/2014/06/Estrategia-Ecuatoriana-de-Comercio-Justo.pdf

Justo.ORG, C. (s.f.). Comercio Justo.ORG. Obtenido de Comercio Justo.ORG: http://comerciojusto.org/lugar/ecuador/

Maquita. (2016). Maquita. Obtenido de Maquita: http://maquita.com.ec/productividad/

NICAISE, G. (2004). ESMA. Obtenido de ESMA:

http://guillaumenicaise.com/Essais/el\%20comercio\%20justo.pdf

Reciprocco.org. (29 de 10 de 2013). Reciprocco.org. Obtenido de Reciprocco.org:

http://www.reciprocco.org/talleres-gran-valle/

Ruben Torres Medina, L. R. (10 de 11 de 2008). UACH. Obtenido de UACH:

http://www.uach.mx/extension_y_difusion/synthesis/2008/11/10/comercio_justo.pdf

Sites. (s.f.). Sites. Obtenido de Sites: https://sites.google.com/site/estructuramexicotonita/5-3ventajas-y-desventajas-del-comercio-justo

Solidaria, E. (s.f.). Economia Solidaria. Obtenido de Economia Solidaria: https://www.economiasolidaria.org/comercio_justo

WFTO. (2016). WFTO. Obtenido de WFTO: http://wfto-la.org/comercio-justo/wfto/10principios/ 